\title{
Development and Evaluation of an Online Fall-Risk Questionnaire for Nonfrail Community-Dwelling Elderly Persons: A Pilot Study
}

\author{
Seraina Obrist, ${ }^{1}$ Slavko Rogan, ${ }^{2}$ and Roger Hilfiker ${ }^{1}$ \\ ${ }^{1}$ School of Health Sciences, University of Applied Sciences and Arts Western Switzerland Valais, Rathausstrasse 8, \\ 3954 Leukerbad, Switzerland \\ ${ }^{2}$ Department of Health, Discipline of Physiotherapy, Bern University of Applied Sciences, Murtenstrasse 10, \\ 3008 Bern, Switzerland
}

Correspondence should be addressed to Roger Hilfiker; roger.hilfiker@gmail.com

Received 6 January 2016; Revised 22 March 2016; Accepted 13 April 2016

Academic Editor: Mariano Malaguarnera

Copyright (C) 2016 Seraina Obrist et al. This is an open access article distributed under the Creative Commons Attribution License, which permits unrestricted use, distribution, and reproduction in any medium, provided the original work is properly cited.

\begin{abstract}
Introduction. Falls are frequent in older adults and may have serious consequences but awareness of fall-risk is often low. A questionnaire might raise awareness of fall-risk; therefore we set out to construct and test such a questionnaire. Methods. Fallrisk factors and their odds ratios were extracted from meta-analyses and a questionnaire was devised to cover these risk factors. A formula to estimate the probability of future falls was set up using the extracted odds ratios. The understandability of the questionnaire and discrimination and calibration of the prediction formula were tested in a cohort study with a six-month followup. Community-dwelling persons over 60 years were recruited by an e-mail snowball-sampling method. Results and Discussion. We included 134 persons. Response rates for the monthly fall-related follow-up varied between the months and ranged from low $38 \%$ to high $90 \%$. The proportion of present risk factors was low. Twenty-five participants reported falls. Discrimination was moderate (AUC: $0.67,95 \%$ CI 0.54 to 0.81 ). The understandability, with the exception of five questions, was good. The wording of the questions needs to be improved and measures to increase the monthly response rates are needed before test-retest reliability and final predictive value can be assessed.
\end{abstract}

\section{Introduction}

Falls are a common cause of accidents and they can have serious consequences ranging from fear of falls to fractures, loss of independency, or even mortality. Approximately 25\% of people over 65 years of age and living at home fall each year and about $20 \%$ of the falls require medical attention [1]. Mortality after a falls-related hospitalisation is high [2] and the falls specific mortality is still rising, although the mortality due to fractures after falls is declining [3]. Forty percent of the admissions to a long-term stay in a nursing home are due to a fall. Therefore, prevention of falls or their consequences is important. There exist a plethora of known risk factors for falls $[4,5]$ and the risk factors generally increase with age. However, older people are often not aware of their own fall-risk [6]. They are aware of the increased fallrisk of other elderly persons, but they are often convinced that this does not apply for themselves [7]. Furthermore, some older adults are reluctant to admit that they are at risk for falls because they fear that their families might send them to nursing homes $[8,9]$. Health professionals, such as nurses or physiotherapists, might play an important role in raising the awareness of the fall-risk.

Screening for falls is usually performed by a health professional. However, in the group of the "young old," not all are regularly seeing health professionals, or they are seeking care for other health conditions and the potentially increased fall-risk is not recognised or not perceived as an issue and not targeted by them or the health professionals [10]. A selfassessment tool might increase the awareness of the fall-risk 
and the motivation to discuss the problem with a health professional and to start a preventive programme $[11,12]$.

Current self-administered predictions tools do not cover all dimensions of fall-risk, such as dual tasks, medication, diseases like diabetes, pain, stroke, rheumatic disease, fear of falling, the frequency of toileting, gait problems, balance, muscle weakness, sensibility impairments, or hearing problems [13-17] (see also Table 1 for a comprehensive overview of existing tools).

Therefore, based on a search for systematic reviews and meta-analysis on risk factors for falls, we set out to (a) collect risk factors that were consistently reported in studies, (b) to extract coefficients from predictive models, (c) to devise a comprehensive set of questions, and (d) to test, in a sample of community-dwelling persons aged sixty years or older, the feasibility, understandability, calibration, and discrimination using the extracted coefficients, including the continuous assessment of falls during a six-month follow-up period. We hypothesize that (a) the monthly response rate is higher than $80 \%$, (b) that the understandability of the questions is good, (c) that the self-predicted fall-risk is not in agreement with the observed fall-risk, (d) that the observed fall-risk is associated with the predicted fall-risk, and (e) that we can discriminate between fallers and nonfallers based on the risk score calculated with the coefficients from the literature and our self-reported questionnaire.

\section{Materials and Methods}

This study included several steps: (1) defining a set of predictors for falls based on published meta-analyses, (2) devising a set of questions for the self-assessment of the risk factors out of seven questionnaires, and (3) prospective cohort study to assess the feasibility and the preliminary predictive values of the online assessment of the fall-risk.

2.1. Defining the Set of Predictors. We searched in PubMed for systematic reviews and meta-analyses on risk factors in community-dwelling elderly people; search strategy: (((risk OR odds OR predict* OR likelihood OR sensitivity OR specificity OR AUC OR ROC OR calibration OR discrimination $)))$ AND ((((()falls [title]) OR fall [title]) OR faller [title] $))$ AND ((meta-analysis [Publication Type]) OR systematic review [title])) AND ((elderly OR older OR aged OR senior OR seniors))). Inclusion criteria were systematic reviews and meta-analysis on prospective cohort studies including community-dwelling elderly persons. We extracted the risk factors for falls that were statistically significant in the metaanalyses. For each factor we extracted the coefficients (i.e., log of the odds ratio) for the prediction of falls in communitydwelling older adults from the meta-analysis with the most included participants or studies for the given predictor.

2.2. Devising the Set of Questions. Based on seven existing questionnaires for the self-assessment of fall-risk [13-17, 44, 45 ], we devised a set of questions that covered most of the fall-risks found in the previous step (review of reviews). The questions were written in German and translated into
French and submitted to seven health professionals and two laypersons with the question about the understandability. Amendments were made if necessary.

We included ten questions about personal characteristics and a question about the self-perceived risk of falling, as well as the understandability (comprehension of the questionnaire) and suggestions for different formulations.

The questionnaire was implemented in an online survey system (SurveyMonkey [46]).

For the monthly follow-up we assessed whether a person fell during the last months and the number of falls. A fall is often defined as "an event which results in a person coming to rest inadvertently on the ground or floor or another lower level." [47]. For our study, we decided to exclude falls in sports activities such as biking, skiing, or mountaineering. Based on feedback from participants at the first monthly follow-up, we added a question about the activity at which the falls occurred and two questions to assess the level of physical activity as recommended by Gill et al. [48] for the later follow-ups.

2.3. Prospective Cohort Study. The main part of this study was a longitudinal cohort study with a six-month follow-up (falls assessment and assessment of physical activity). Study participants were community-dwelling elderly persons aged 60 years or more. They had to be able to walk independently, with or without walking aids. German and French speaking participants were included if they had an e-mail address.

Participants were recruited by a snowball-sampling method [49]. This method allows the inclusion of participants that are difficult to achieve. If our hypothesis is true that our target population has a low awareness of their risk to fall, they would, for example, most probably not respond to other sampling methods such as information leaflets or advertisements in journals. Other sampling methods such as phone number lists are nowadays not valid anymore, because a large subset of the population is not listed in directories (phone books). A first set of e-mails with a link to the online survey (SurveyMonkey) was sent to acquaintances with a description of the target population (i.e., describing inclusion criteria); they were then asked to send the e-mail to their acquaintances, and so on. For six months, the monthly fall assessment was sent by e-mail via SurveyMonkey.

Sample Size. We used a convenience sample consisting of the 134 participants responding to the e-mails sent out with the snowball method. This sample size allowed the estimation of the incidence of falls and univariable association between risk factors and falls with enough statistical precision.

The project was conducted in accordance with the Declaration of Helsinki (1964) and was approved by the relevant ethical committee (CCVEM 014/14). All participants provided informed consent to the participation.

2.4. Adaptation of the Questionnaire. Based on the feedbacks on the understandability and the suggestions for alternative formulations, propositions for amendments were prepared. The final amendments will be part of a future project including a larger sample of experts including elderly persons. 


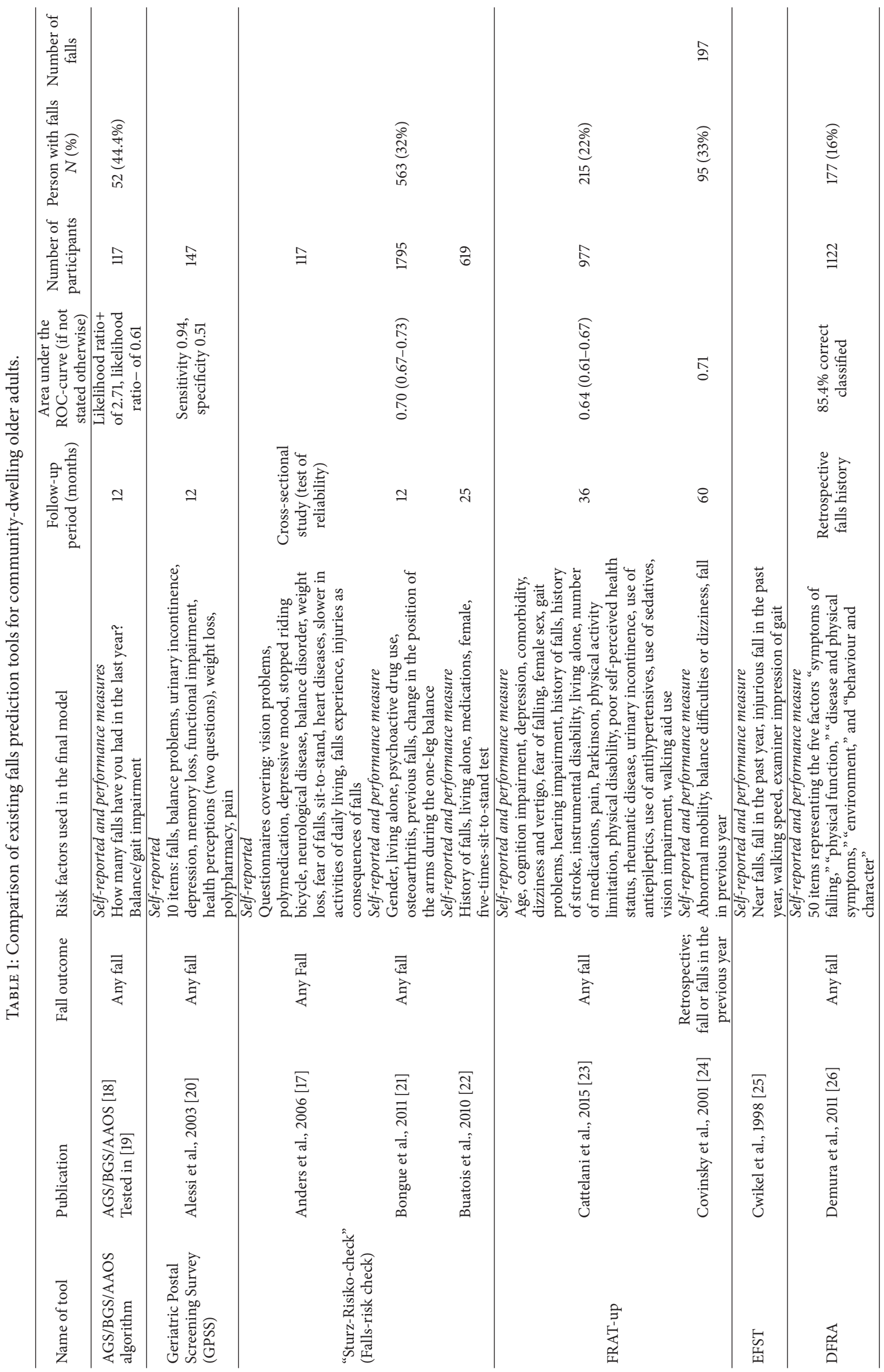




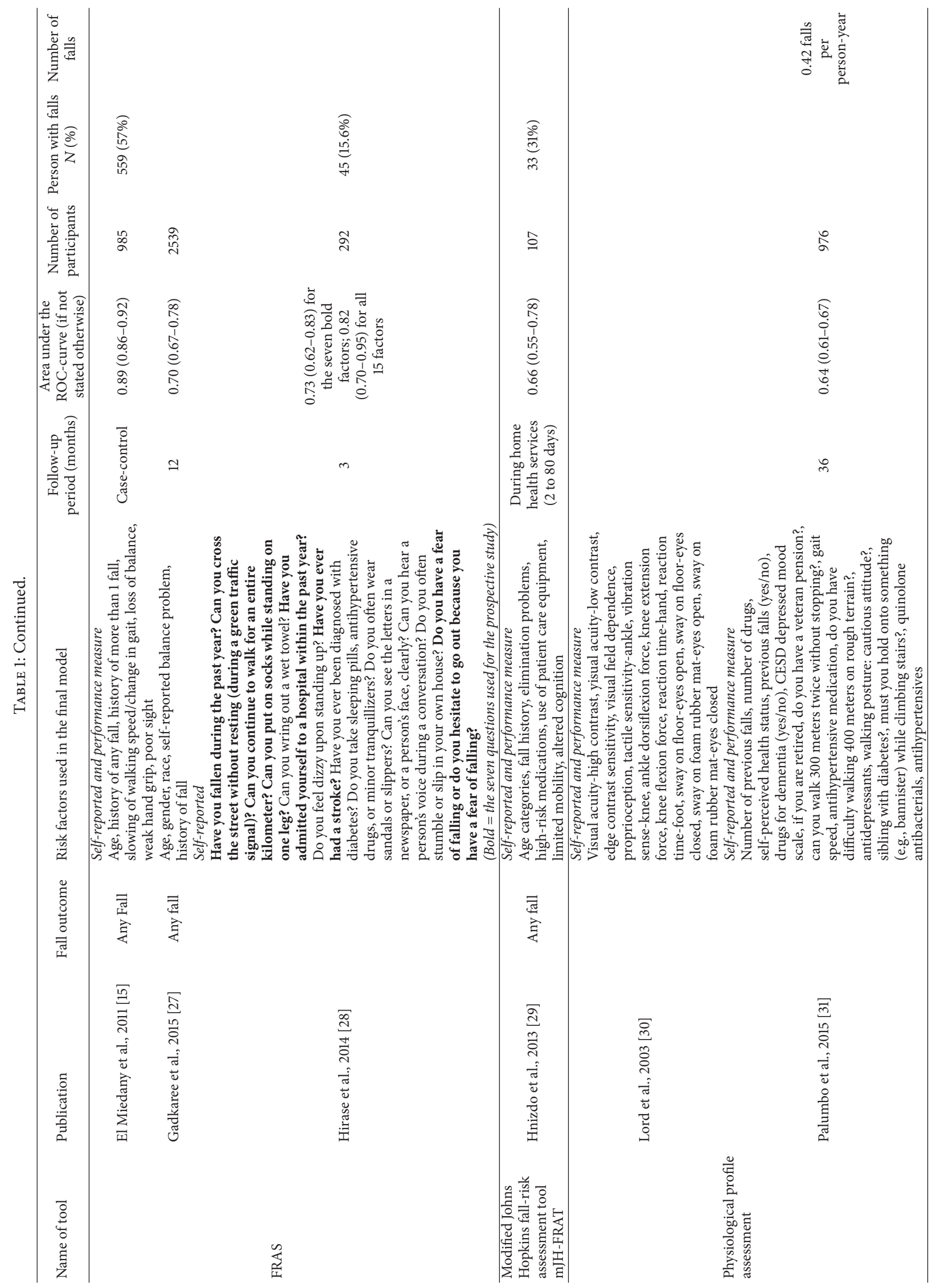




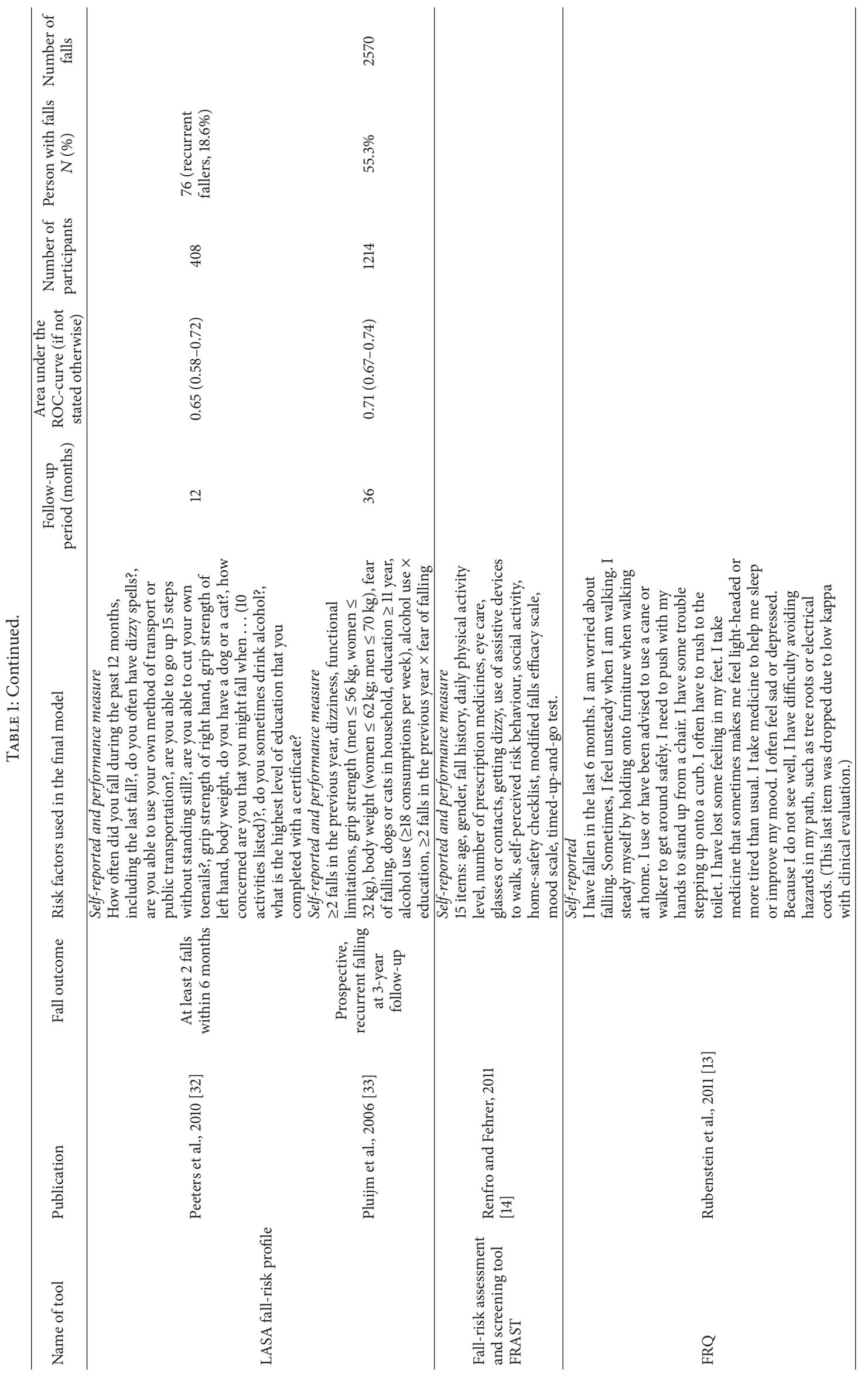




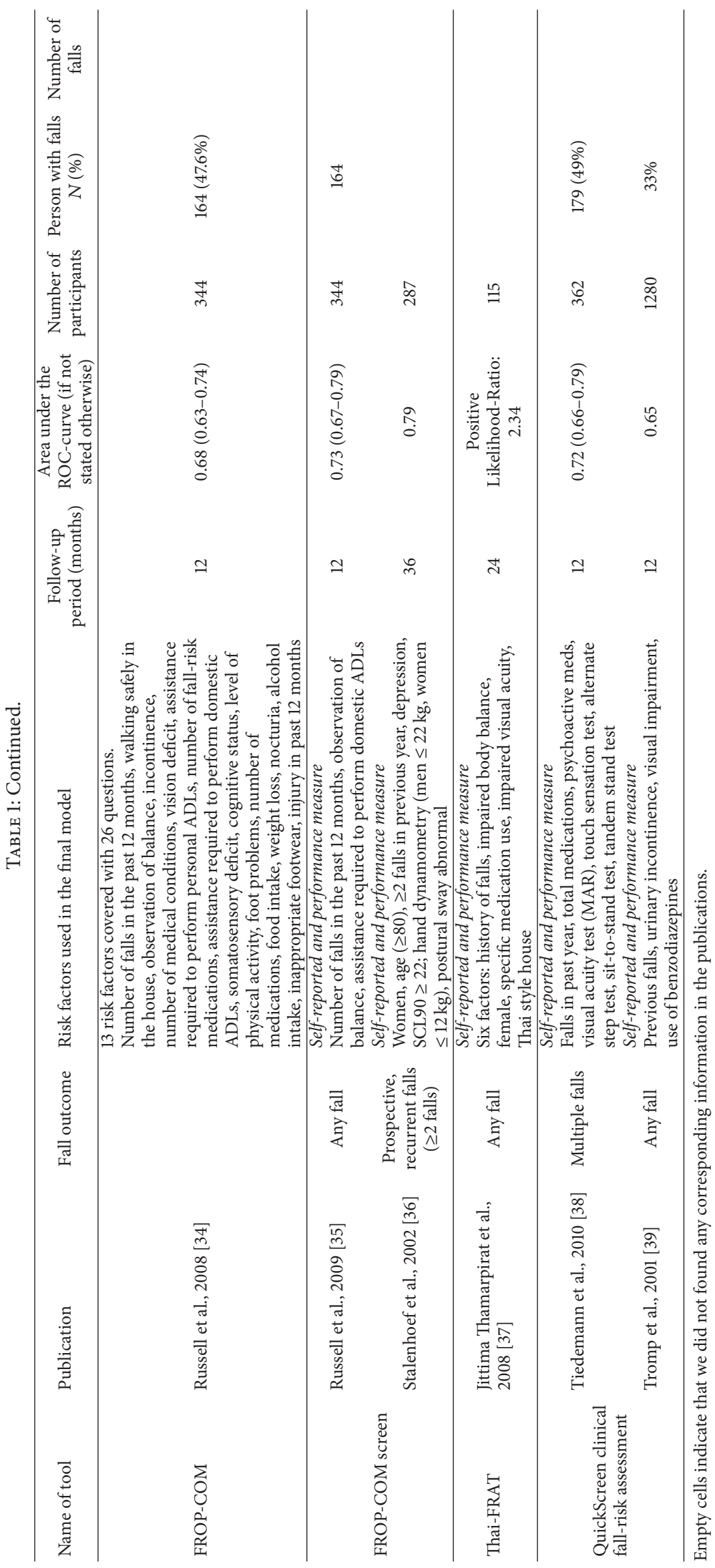


2.5. Statistical Analysis. Descriptive statistics were presented as mean and standard deviation or as proportions, as appropriate. To express the association between risk factors and falls we calculated odds ratios and risk ratios and corresponding 95\% confidence intervals. We used Stata Version 14.0 [50]. We calculated both risk and odds ratios because risk ratios are easier to interpret but the odds ratios allow a better comparison with published prediction tools. If a participant did not return a monthly falls follow-up, we assumed that there was no fall in this month.

To test the hypothesis that the participants are not aware of their fall-risk, that is, their self-perceived fall-risk is lower than the actual fall-risk, we calculated the proportion of fallers within each category of the self-perceived risk and calculated a chi-squared test with the null hypothesis that there is no association in the perceived fall-risk with increasing observed fall-risk.

2.6. Prediction Formula. Because our sample size was only large enough for univariable analyses and too low for the fitting of a robust multivariable prediction model, we used the coefficients published in the meta-analyses. The prediction formula consisted of a scoring function and a logistic probability function, where the scoring function reads as follows:

scoring function $=-4.5+0.1044 *($ age over $60 / 5)$ $+1.351 *$ fallen last 12 months $+0.495 *$ low spirit at some days $+0.548 *$ incontinence $+0.62 *$ need get up night $+0.215 *$ rheumatic disease $+0.307 *$ diziness $+0.779 *$ neurological disease $+0.239 *$ diabetes $+0.445 *$ dichotomous pain $+0.247 *$ high blood pressure $+0.47 *$ heart symptoms $+0.875 *$ fear of falls $+0.94 *$ walk slower $+0.742 *$ walking aids $+0.2852 *$ perceived dual task problem $+0.859 *$ self perceived balance $+0.457 *$ any range of motion limitation lower extremity $+0.788 *$ sensory deficit lower extremity $+0.399 *$ vision problem $+0.315 *$ do not hear good $+0.548 *$ dichotomous home hazards $+0.718 *$ low BMI + $0.8242 *$ ADL need help +0.637 $*$ fracture $+0.54 *$ polymedication $+1.445 *$ any medication $+0.24 *$ postural hypotension $+0.98 *$ difficult get up chair because of weak legs.

And the logistic probability function is as follows: $1 /(1+\exp (-1 *$ scoring function $))$.

This formula has to be considered as preliminary because the coefficients of each predictor are not adjusted for all other predictors, which leads to an overestimation of the fall-risk. The coefficients need to be adjusted, for example, by the means of methods proposed by [51]. These methods need larger sample sizes than we had in our study.

Based on this preliminary prediction formula, we tested the calibration of the prediction model with a calibration plot (observed versus predicted falls) and a Hosmer-Lemeshow test. The discrimination (i.e., the ability to detect fallers) was tested with a receiver operating characteristic (ROC) curve and the area under the ROC-curve.

\section{Results}

The systematic search for systematic reviews and metaanalysis on fall-risk factors yielded 113 abstracts from which 14 systematic reviews were included $[4,5,40,42,43,52-$ $60]$. Because we extracted the coefficients from the metaanalysis with the most participants or studies included, the coefficients were taken from the newest reviews $[4,5,40,42$, 43]. In addition, we extracted the coefficients from one single study for the variable frequent toileting [41] because we preferred this variable over the variables urinary incontinence or urinary functional sign published in the Block 2013 metaanalysis. Table 2 shows the set of extracted factors as well as its odds ratio, coefficients, and heterogeneity, if available.

3.1. Set of Items Devised for the Self-Administered Fall-Risk Questionnaire. Based on the set of predictors we devised a set of questions. Because there was considerable overlap between the predictors, we selected a subset of 29 predictors with the aim of reducing overlap. Because some constructs were covered with more than one question, our questionnaire consisted of 36 questions, including demographic characteristics. Some of the questions consisted of several response options covering different risk factors.

3.2. Characteristics of Included Participants. With the snowball-sampling we could include 134 participants. The response rate during the monthly follow-up varied from 38 to $90 \%$ (see Figure 1). The mean age of the 134 participants was 69.3 years with a standard deviation of 5.6 years. There were slightly less women than men (45\% women and 55\% men). The mean body mass index (BMI) was $25.95 ; 13 \%$ had a BMI of 30 or more (i.e., would be classified as obese). The proportion of participants who did fall during the last twelve months was $18 \%$; only a very small proportion had consequences due to these falls. During the 6-month follow-up, 32 participants did fall at least once, we excluded seven falls (three falls on bike, one fall on ski, two falls on icy roads, and one fall during mountaineering on steep paths), resulting in 25 falls (18.7\%). For each risk factor, only a small proportion of participants indicated problems which leads to wide confidence intervals in the odds ratios (Table 2) and the risk ratios presented (Table 3 ).

3.3. Self-Perceived Fall-Risk and Actual Falls. For the question about the self-perceived probability to fall within the next six months, 49 participants (37\%) reported that they "will not fall" and 7 (14\% of the 49$)$ did actually fall; 81 (60\%) reported that they "will probably not fall" and 17 (21\% of the 81$)$ did fall. Only two persons reported that they will "probably fall" and one of those did fall. Two participants did not respond to the question about the self-perceived fall-risk. There was no association between self-perceived and observed fall-risk $(p=0.338)$.

3.4. Predictive Values. After calculation of the predicted probability to fall based on the values from our questionnaire and the coefficients published in the meta-analysis (Table 2), 


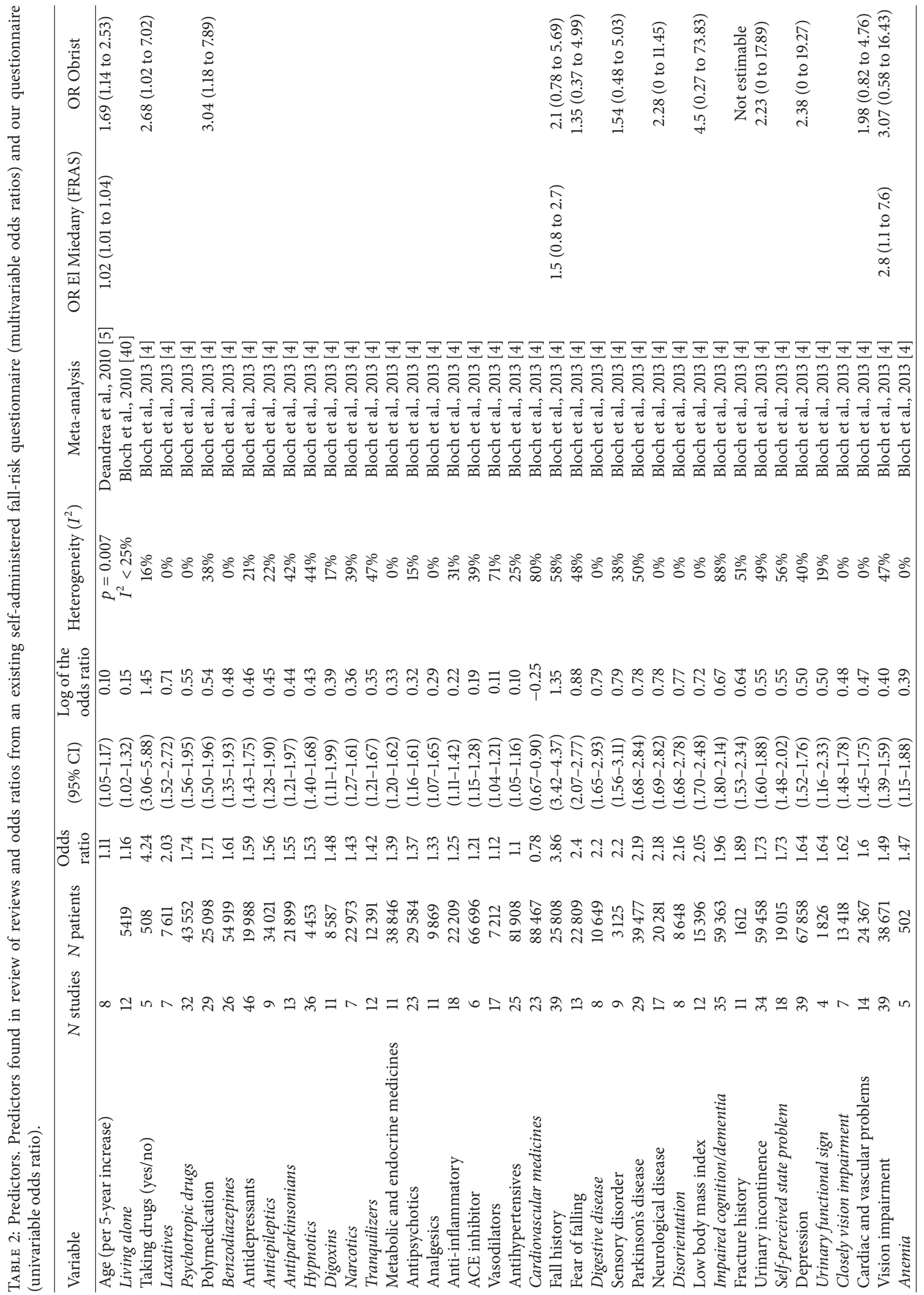




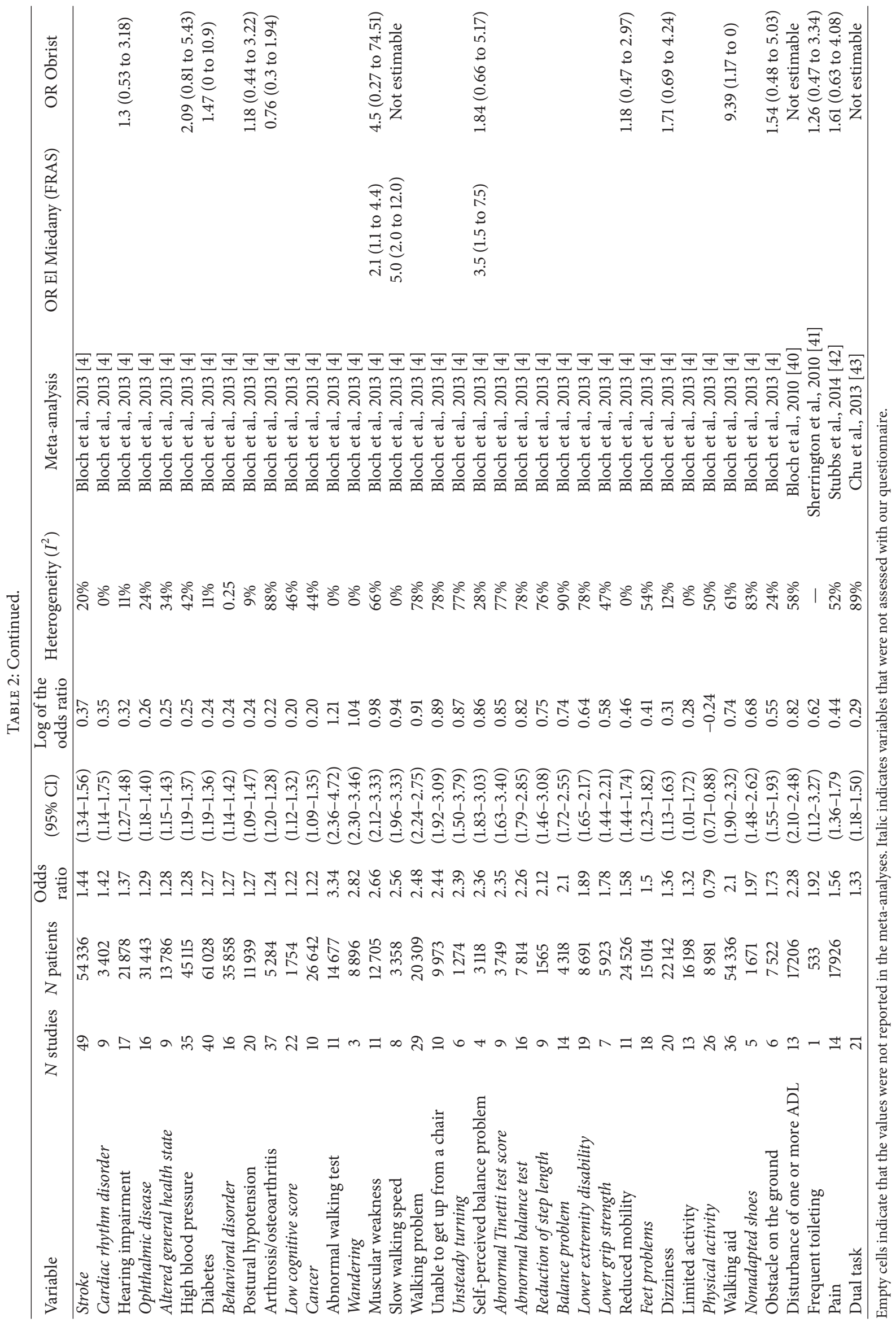




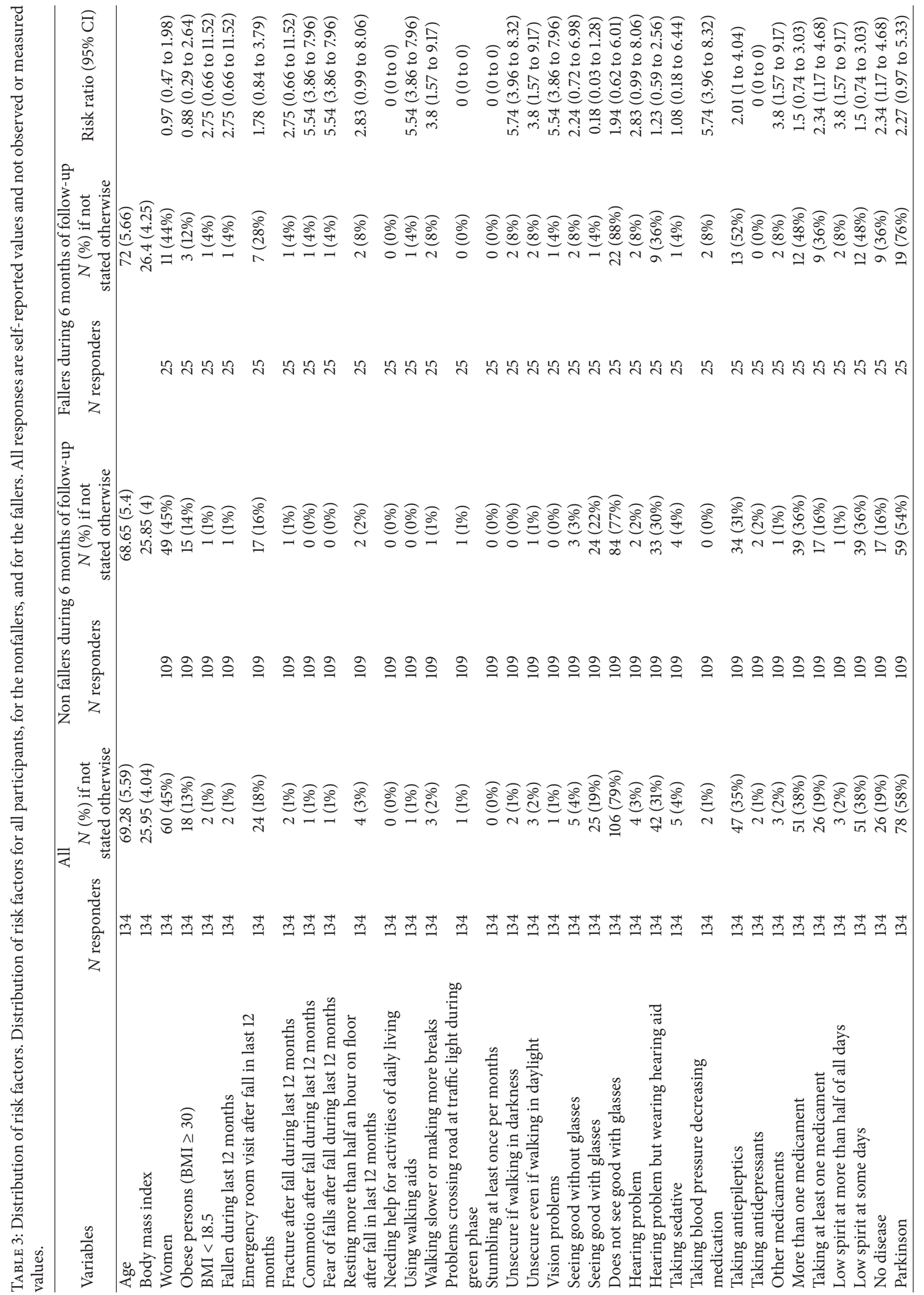




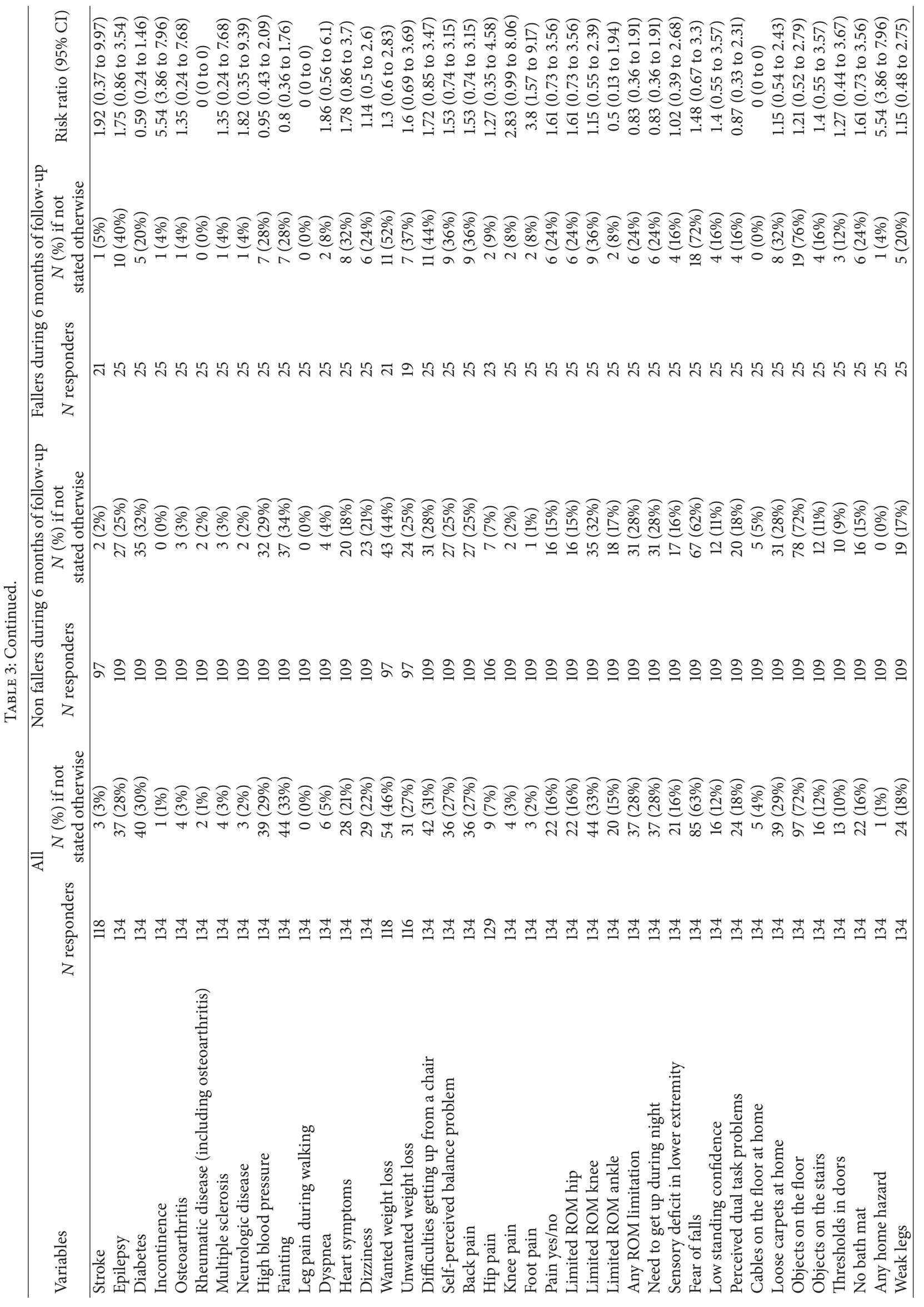




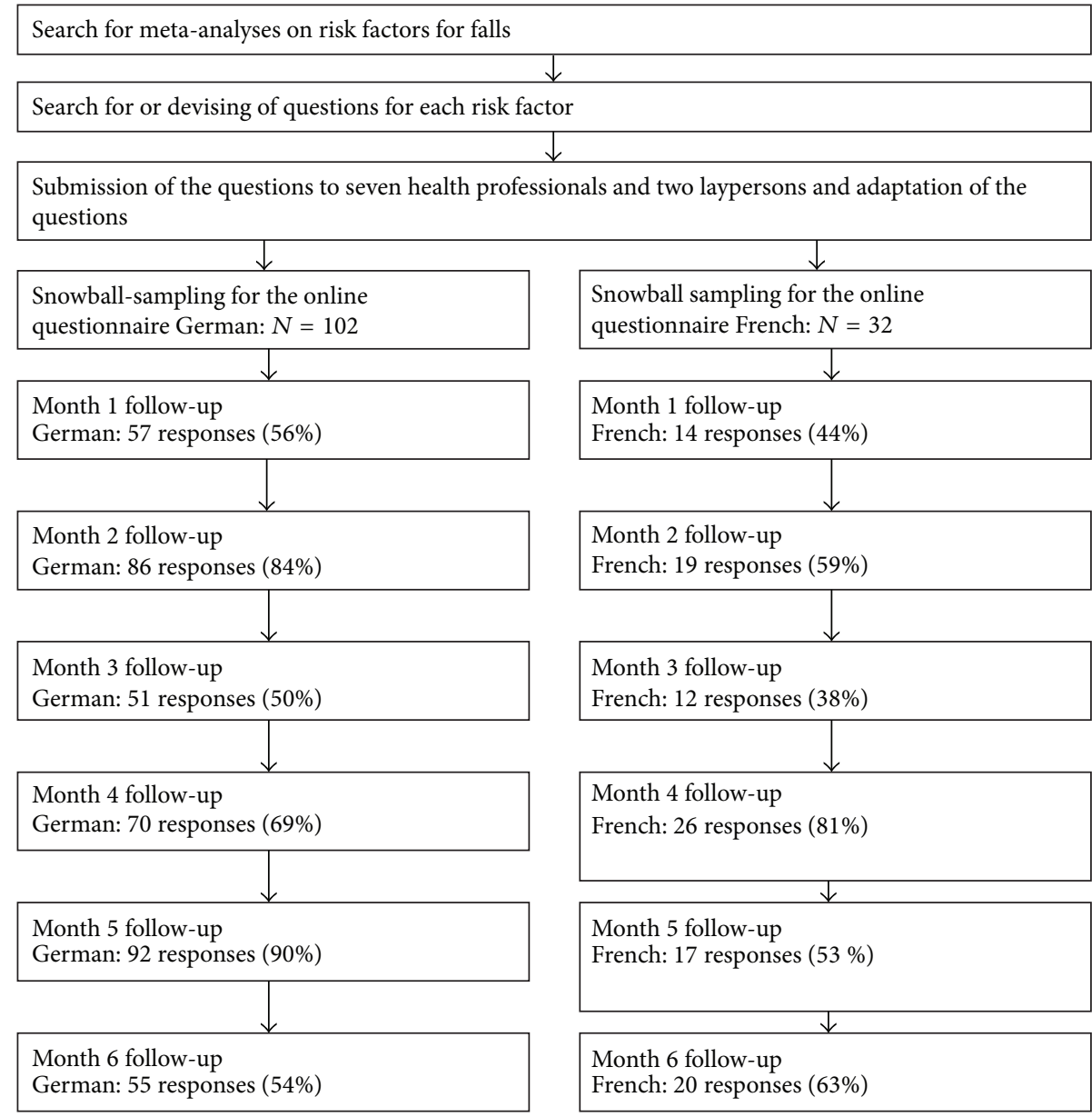

Figure 1: Study diagram.

the prediction model yielded an AUC value for the discrimination of 0.67 (96\% CI 0.54 to 0.81 ) (Figure 2). There was statistically significant miscalibration ( $p$ value from the Hosmer-Lemeshow test <0.00001) (Figure 3).

3.5. Understandability of the Questionnaires. Ten participants stated that some questions were unclear and they provided seven specific comments, such as the following: that they were diagnosed with hypertension but had normal blood pressure under medication and did not know what to answer in the questions about present diseases; that some questions were asking about two different pieces of information and that some questions had double negations.

\section{Discussion}

In this longitudinal cohort study with a six-month followup of falls, including 134 community-dwelling elderly participants aged 60 years or more, we tested a preliminary version of an online questionnaire to assess the fall-risk. The main findings were that (a) it is feasible to do an online survey of a comprehensive set of fall-risk factors and (b) the understandability of the questions was good with the exceptions of five questions, (c) the response rate of the monthly falls assessment was too low, (d) the discrimination was moderate, and (e) the calibration was insufficient.

The strength of our study was the approach to devise a set of questions covering the whole spectre of risk factors for falls based on published meta-analyses. This study is an important first step in the development of a comprehensive self-administered questionnaire. Although we cannot present a final version of the questionnaire, this study provides important information for the future development of fall-risk questionnaires.

There are some limitations of our project. The understandability was assessed by semistructured interviews with experts and with an open question in the online questionnaire for the participants. We interviewed only two laypersons before we sent out the questionnaire to the participants. Interviewing of more participants before sending the questionnaire to the participants might have eliminated some problems with the understandability. It is challenging to assess risk factors with self-administered questionnaires. The different visual risk factors especially such as distant contrast sensitivity or depth perception [61] or the dual task problems are difficult to assess. Furthermore, snowball-sampling is a "biased" sampling technique because it is not random 


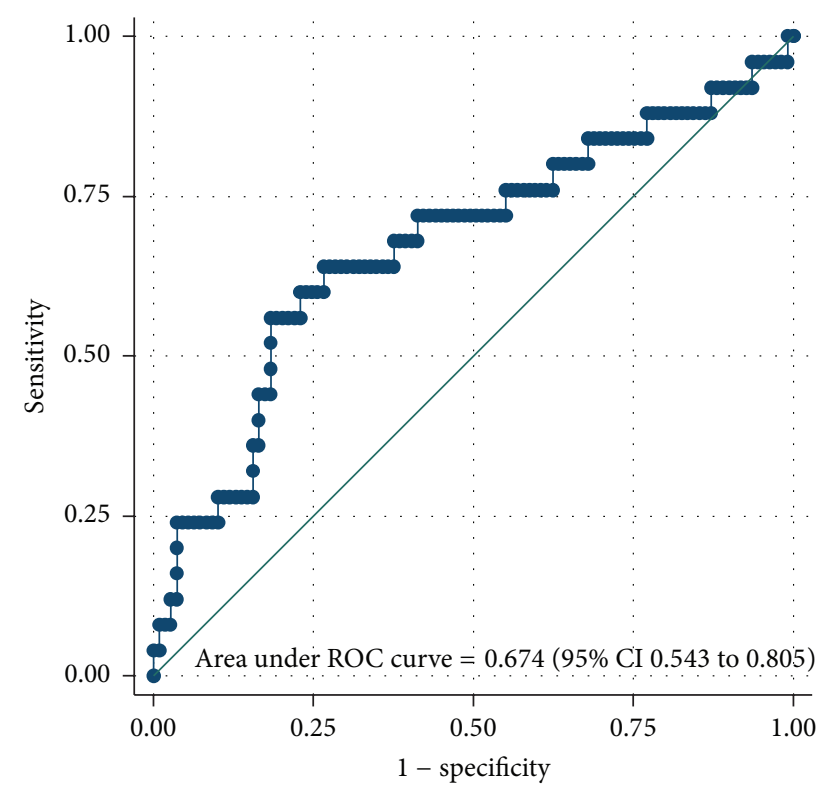

FIGURE 2: Receiver operating characteristic curve.

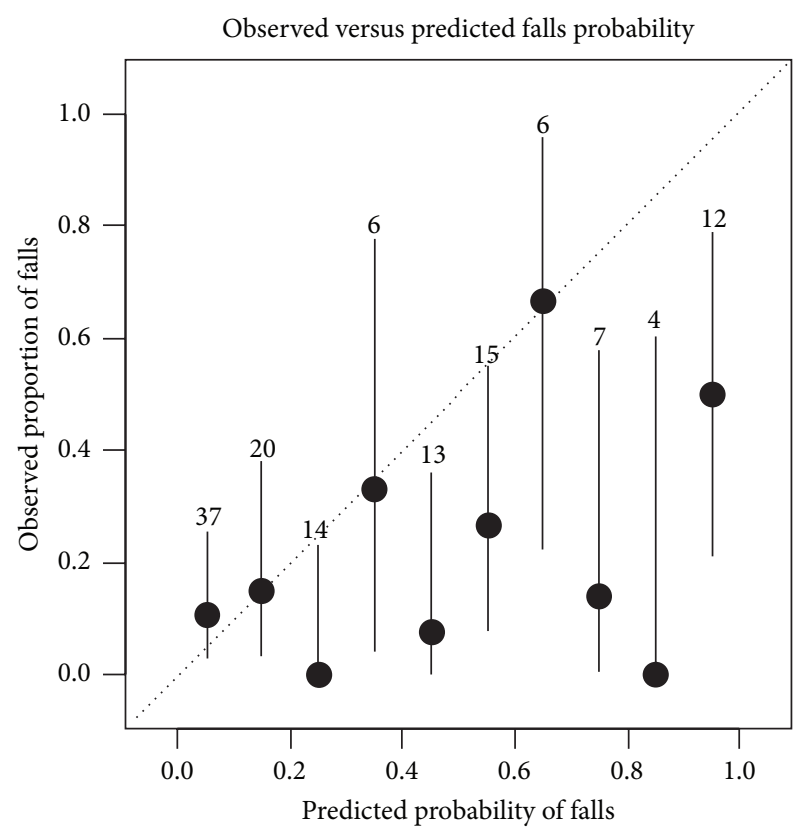

FIgURE 3: Probability for fall. Calibration plot of observed versus estimated probability for fall.

and the inclusion of the next participants depends on the previous participants (i.e., participants are not independent). An alternative would have been to search participants by the means of flyers or newspaper or radio advertisements. However, the snowball-sampling has the advantage of being nonexpensive and fast. The nonrandomness is not a large disadvantage in a feasibility study. A further limitation is the low response rate for the monthly fall-risk assessment. We did not systematically send reminders if participants did not respond. Furthermore, we did not present a fall definition to the participant, because we thought that this could confuse more than it would help. Presenting and explaining a fall definition such as the one used by Tinetti et al., "a sudden, unintentional change in position causing an individual to land at a lower level, on an object, the floor, or the ground, other than as a consequence of sudden onset of paralysis, epileptic seizure, or overwhelming external force" [62], might clarify what to report as a fall. Furthermore, the questions about the falls could include examples to illustrate what we understand by a fall. For example, some participants do not consider falling on their knees as a fall, because they were not "lying" on the ground after the fall. It is unclear whether the inclusion of photographs or graphical illustration could improve the reporting. Questions for falls could include examples of specific situations. However, our falls incidence of $19 \%$ is compatible with one-year incidences (39\% for women, $30 \%$ for men), data recently published from Germany [63]; therefore we do not believe that there is an underestimation of the falls. We only assessed falls during six months; a longer follow-up would have increased the number of falls. The frequency of problems reported in the individual fall-risk questions was very low if compared to other studies on self-report fall-risk questionnaires $[15,17]$. This could be due to the good health state of our participants but it could also be due to how the questions were formulated (i.e., unclear wording or wording targets only serious problems). Given the very low proportion of present risk factors, the selection of our sample could be problematic. There might be a selection bias towards a higher socioeconomic state, given the high proportion of participants with higher education. Given the low presence of risk factors we would have expected a lower falls incidence rate. Our prediction formula still overestimates the fall-risk. This is most probably due to the high correlation between the included predictors. However, our sample size was sufficiently large for univariable analyses but too low to adjust for this correlation by the means of a multivariable model. Therefore, the prediction formula needs to be adjusted with methods proposed by Steyerberg and colleagues [51] in a larger sample once the questionnaire is in its definitive version and after testing of the reliability.

If we compare our results to published studies using questionnaires for the assessment of fall-risk, we have similar values for calibration and discrimination compared to Cattelani et al. [16]. Compared to El Miedany et al. [15] we have lower predictive values; they received an AUC value of 0.89 with only five predictors. However, they included a sample where all had at least one previous fall and where $82 \%$ reported to walk slower, $65 \%$ reported loss of balance, and $55 \%$ had poor sight. Therefore, the two samples are not similar. Our AUC value is low but one has to consider that other tests widely used to predict falls, such as the timed-upand-go (TUG) test, do not have better predictive values. A recent review on the predictive values for falls of the TUG in community-dwelling elderly people found an AUC value of 0.57 [64].

We did not find an association between self-perceived fall-risk and falls. One might expect that the self-perceived risk for falling increases fear of falls, which is known to be 
associated with future falls. One reason why we did not find an association is that the response options of the question for the self-perceived risk were not optimal and should be improved for future studies.

Our study has some implications for further research. The following amendments need to be done before further testing: (1) the question about past falls which should ask about the number of falls in the last year; it is recommended that persons with more than one fall in the past year should be referred to a detailed assessment [65]; (2) rewording of some questions; and (3) explication of what is considered as a fall to exclude falls, for example, due to an overwhelming external force, that is, following the falls definition used by [62]. After a refinement of the questions, test-retest reliability must be tested before the coefficients for a final predictive model should be assessed with a multivariable logistic regression based on results from a larger cohort study with a oneyear follow-up in which the analyses should be separated for the prediction of one fall or recurrent falls. Furthermore, a larger sample size would allow evaluating whether some questions might be eliminated without losing discrimination or calibration of the prediction tool.

Implications for practice are as follows. Our study showed that in a sample with a relative low risk profile the incidence of falls was $19 \%$ during a period of six months and that the participants were mostly not aware of their fall-risk. Health professionals who see patients for other indications, for example, for the treatment of osteoarthritis, back pain, or neurological problems, could use this fall-risk questionnaire as a screening tool or a "flag system" and specifically test the domains where the patients report problems. The health professionals could then refer the patient to a falls-prevention group. The tool could also be used for the preparation of a visit to a medical doctor. The patients could bring the questionnaire to the medical doctor to discuss the results and possible strategies if necessary.

\section{Conclusion}

This study showed that fall-risk awareness is low and that even in a sample of elderly people with a low risk profile in known risk factors the falls incidence is $19 \%$ in a six-month period. The present questionnaire needs some adaptation of the wording and reliability testing before a definitive prediction formula can be developed in a large sample and with multivariable analyses. Measures need to be implemented to increase the monthly response rate for the follow-up period.

\section{Competing Interests}

The authors declare that they have no competing interests.

\section{Acknowledgments}

The authors would like to thank the experts and the participants of this study. Furthermore, they really appreciated the helpful comments from the anonymous reviewers.

\section{References}

[1] A. J. Milat, W. L. Watson, C. Monger, M. Barr, M. Giffin, and M. Reid, "Prevalence, circumstances and consequences of falls among community-dwelling older people: results of the 2009 NSW Falls Prevention Baseline Survey," New South Wales Public Health Bulletin, vol. 22, no. 3-4, pp. 43-48, 2011.

[2] M. P. Tan, S. B. Kamaruzzaman, M. I. Zakaria, A.-V. Chin, and P. J. H. Poi, "Ten-year mortality in older patients attending the emergency department after a fall," Geriatrics \& Gerontology International, vol. 16, no. 1, pp. 111-117, 2016.

[3] M. Gagné, Y. Robitaille, S. Jean, and P.-A. Perron, "Changes in fall-related mortality in older adults in Quebec, 1981-2009," Chronic Diseases and Injuries in Canada, vol. 33, no. 4, pp. 226235, 2013.

[4] F. Bloch, M. Thibaud, C. Tournoux-Facon et al., "Estimation of the risk factors for falls in the elderly: can meta-analysis provide a valid answer?" Geriatrics \& Gerontology International, vol. 13, no. 2, pp. 250-263, 2013.

[5] S. Deandrea, E. Lucenteforte, F. Bravi, R. Foschi, C. La Vecchia, and E. Negri, "Risk factors for falls in community-dwelling older people: a systematic review and meta-analysis," Epidemiology, vol. 21, no. 5, pp. 658-668, 2010.

[6] T. Mihaljcic, T. P. Haines, J. L. Ponsford, and R. J. Stolwyk, "Selfawareness of falls risk among elderly patients: characterizing awareness deficits and exploring associated factors," Archives of Physical Medicine and Rehabilitation, vol. 96, no. 12, pp. 21452152, 2015.

[7] L. Yardley, F. L. Bishop, N. Beyer et al., "Older people's views of falls-prevention interventions in six European countries," The Gerontologist, vol. 46, no. 5, pp. 650-660, 2006.

[8] A. Loganathan, C. J. Ng, M. P. Tan, and W. Y. Low, "Barriers faced by healthcare professionals when managing falls in older people in Kuala Lumpur, Malaysia: a qualitative study," BMJ Open, vol. 5, no. 11, Article ID e008460, 2015.

[9] W. C. Chou, M. E. Tinetti, M. B. King, K. Irwin, and R. H. Fortinsky, "Perceptions of physicians on the barriers and facilitators to integrating fall risk evaluation and management into practice," Journal of General Internal Medicine, vol. 21, no. 2, pp. 117-122, 2006.

[10] D.-C. A. Lee, F. McDermott, T. Hoffmann, and T. P. Haines, "They will tell me if there is a problem: limited discussion between health professionals, older adults and their caregivers on falls prevention during and after hospitalization," Health Education Research, vol. 28, no. 6, pp. 1051-1066, 2013.

[11] K. Hill, M. Dorevitch, and N. F. P. F. O. P. Initiative, An Analysis of Research on Preventing Falls and Falls Injury in Older People: Community, Residential Care and Hospital Settings:(2004 Update), An Analysis of Research on Preventing Falls and Falls Injury in Older People: Community, Residential Care and Hospital Settings:(2004 Update), 2004.

[12] P. Pohl, M. Sandlund, C. Ahlgren, B. Bergvall-Kåreborn, L. Lundin-Olsson, and A. M. Wikman, "Fall risk awareness and safety precautions taken by older community-dwelling women and men-a qualitative study using focus group discussions," PLoS ONE, vol. 10, no. 3, Article ID e0119630, 2015.

[13] L. Z. Rubenstein, R. Vivrette, J. O. Harker, J. A. Stevens, and B. J. Kramer, "Validating an evidence-based, self-rated fall risk questionnaire (FRQ) for older adults," Journal of Safety Research, vol. 42, no. 6, pp. 493-499, 2011.

[14] M. O. Renfro and S. Fehrer, "Multifactorial screening for fall risk in community-dwelling older adults in the primary care 
office: development of the fall risk assessment \& screening tool," Journal of Geriatric Physical Therapy, vol. 34, no. 4, pp. 174-183, 2011.

[15] Y. El Miedany, M. El Gaafary, M. Toth, D. Palmer, and I. Ahmed, "Falls risk assessment score (FRAS): time to rethink," Journal of Clinical Gerontology and Geriatrics, vol. 2, no. 1, pp. 21-26, 2011.

[16] L. Cattelani, P. Palumbo, L. Palmerini et al., "FRAT-up, a Webbased fall-risk assessment tool for elderly people living in the community," Journal of Medical Internet Research, vol. 17, no. 2, article e41, 2015.

[17] J. Anders, U. Dapp, S. Laub, W. von Renteln-Kruse, and K. Juhl, "Einschätzung der Sturzgefährdung gebrechlicher, noch selbstständig lebender, älterer Menschen," Zeitschrift für Gerontologie und Geriatrie, vol. 39, no. 4, pp. 268-276, 2006.

[18] American Geriatrics Society, British Geriatrics Society, and American Academy of Orthopaedic Surgeons Panel on Falls Prevention, "Guideline for the prevention of falls in older persons," Journal of the American Geriatrics Society, vol. 49, no. 5, pp. 664-672, 2001.

[19] S. W. Muir, K. Berg, B. Chesworth, N. Klar, and M. Speechley, "Application of a fall screening algorithm stratified fall risk but missed preventive opportunities in community-dwelling older adults: a prospective study," Journal of Geriatric Physical Therapy, vol. 33, no. 4, pp. 165-172, 2010.

[20] C. A. Alessi, K. R. Josephson, J. O. Harker, F. M. Pietruszka, M. T. Hoyl, and L. Z. Rubenstein, "The yield, reliability, and validity of a postal survey for screening community-dwelling older people," Journal of the American Geriatrics Society, vol. 51, no. 2, pp. 194-202, 2003.

[21] B. Bongue, C. Dupré, O. Beauchet, A. Rossat, B. Fantino, and A. Colvez, "A screening tool with five risk factors was developed for fall-risk prediction in community-dwelling elderly," Journal of Clinical Epidemiology, vol. 64, no. 10, pp. 1152-1160, 2011.

[22] S. Buatois, C. Perret-Guillaume, R. Gueguen et al., "A simple clinical scale to stratify risk of recurrent falls in communitydwelling adults aged 65 years and older," Physical Therapy, vol. 90, no. 4, pp. 550-560, 2010.

[23] L. Cattelani, P. Palumbo, L. Palmerini et al., "FRAT-up, a webbased fall-risk assessment tool for elderly people living in the community," Journal of Medical Internet Research, vol. 17, no. 2, article e41, 2015.

[24] K. E. Covinsky, E. Kahana, B. Kahana, K. Kercher, J. G. Schumacher, and A. C. Justice, "History and mobility exam index to identify community-dwelling elderly persons at risk of falling," The Journals of Gerontology-Series A: Biological Sciences and Medical Sciences, vol. 56, no. 4, pp. M253-M259, 2001.

[25] J. G. Cwikel, A. V. Fried, A. Biderman, and D. Galinsky, "Validation of a fall-risk screening test, the Elderly Fall Screening Test (EFST), for community-dwelling elderly," Disability and Rehabilitation, vol. 20, no. 5, pp. 161-167, 1998.

[26] S. Demura, S. Sato, S. Yamaji, K. Kasuga, and Y. Nagasawa, "Examination of validity of fall risk assessment items for screening high fall risk elderly among the healthy communitydwelling Japanese population," Archives of Gerontology and Geriatrics, vol. 53, no. 1, pp. e41-e45, 2011.

[27] S. K. Gadkaree, D. Q. Sun, J. Huang, R. Varadhan, and Y. Agrawal, "Comparison of simple versus performance-based fall prediction models: data from the national health and aging trends study," Gerontology and Geriatric Medicine, vol. 1, 2015.

[28] T. Hirase, S. Inokuchi, N. Matsusaka, K. Nakahara, and M. Okita, "A modified fall risk assessment tool that is specific to physical function predicts falls in community-dwelling elderly people," Journal of Geriatric Physical Therapy, vol. 37, no. 4, pp. 159-165, 2014.

[29] S. Hnizdo, R. A. Archuleta, B. Taylor, and S. C. Kim, "Validity and reliability of the modified John Hopkins Fall Risk Assessment Tool for elderly patients in home health care," Geriatric Nursing, vol. 34, no. 5, pp. 423-427, 2013.

[30] S. R. Lord, H. B. Menz, and A. Tiedemann, "A physiological profile approach to falls risk assessment and prevention," Physical Therapy, vol. 83, no. 3, pp. 237-252, 2003.

[31] P. Palumbo, L. Palmerini, S. Bandinelli, L. Chiari, and Y. Wang, "Fall risk assessment tools for elderly living in the community: can we do better?" PLOS ONE, vol. 10, no. 12, Article ID e0146247, 2015.

[32] G. M. E. E. Peeters, S. M. F. Pluijm, N. M. Van Schoor, P. J. M. Elders, L. M. Bouter, and P. Lips, "Validation of the LASA fall risk profile for recurrent falling in older recent fallers," Journal of Clinical Epidemiology, vol. 63, no. 11, pp. 1242-1248, 2010.

[33] S. M. F. Pluijm, J. H. Smit, E. A. M. Tromp et al., "A risk profile for identifying community-dwelling elderly with a high risk of recurrent falling: results of a 3-year prospective study," Osteoporosis International, vol. 17, no. 3, pp. 417-425, 2006.

[34] M. A. Russell, K. D. Hill, I. Blackberry, L. M. Day, and S. C. Dharmage, "The reliability and predictive accuracy of the falls risk for older people in the community assessment (FROPCom) tool," Age and Ageing, vol. 37, no. 6, pp. 634-639, 2008.

[35] M. A. Russell, K. D. Hill, L. M. Day, I. Blackberry, L. C. Gurrin, and S. C. Dharmage, "Development of the falls risk for older people in the community (FROP-Com) screening tool," Age and Ageing, vol. 38, no. 1, pp. 40-46, 2009.

[36] P. A. Stalenhoef, J. P. M. Diederiks, J. A. Knottnerus, A. D. M. Kester, and H. F. J. M. Crebolder, "A risk model for the prediction of recurrent falls in community-dwelling elderly: a prospective cohort study," Journal of Clinical Epidemiology, vol. 55, no. 11, pp. 1088-1094, 2002.

[37] M. Jittima Thamarpirat, D. Wantana Maneesriwongul, and M. Sutthichai Jitapunkul, "Thai falls risk assessment test (ThaiFRAT) developed for community-dwelling Thai elderly," Journal of the Medical Association of Thailand, vol. 91, no. 12, pp. 1823-1832, 2008.

[38] A. Tiedemann, S. R. Lord, and C. Sherrington, "The development and validation of a brief performance-based fall risk assessment tool for use in primary care," The Journals of Gerontology Series A: Biological Sciences and Medical Sciences, vol. 65, no. 8, pp. 896-903, 2010.

[39] A. M. Tromp, S. M. F. Pluijm, J. H. Smit, D. J. H. Deeg, L. M. Bouter, and P. Lips, "Fall-risk screening test: a prospective study on predictors for falls in community-dwelling elderly," Journal of Clinical Epidemiology, vol. 54, no. 8, pp. 837-844, 2001.

[40] F. Bloch, M. Thibaud, B. Dugué, C. Brèque, A. S. Rigaud, and G. Kemoun, "Episodes of falling among elderly people: a systematic review and meta-analysis of social and demographic pre-disposing characteristics," Clinics, vol. 65, no. 9, pp. 895903, 2010.

[41] C. Sherrington, S. R. Lord, J. C. Close et al., "Development of a tool for prediction of falls in rehabilitation settings (Predict_FIRST): a prospective cohort study," Journal of Rehabilitation Medicine, vol. 42, no. 5, pp. 482-488, 2010.

[42] B. Stubbs, T. Binnekade, L. Eggermont, A. A. Sepehry, S. Patchay, and P. Schofield, "Pain and the risk for falls in 
community-dwelling older adults: systematic review and metaanalysis," Archives of Physical Medicine and Rehabilitation, vol. 95, no. 1, pp. 175.e9-187.e9, 2014.

[43] Y.-H. Chu, P.-F. Tang, Y.-C. Peng, and H.-Y. Chen, "Metaanalysis of type and complexity of a secondary task during walking on the prediction of elderly falls," Geriatrics and Gerontology International, vol. 13, no. 2, pp. 289-297, 2013.

[44] T. Steinkellner, Gleichgewicht im Alter, Universität Wien, 2011.

[45] T. Mihaljcic, T. P. Haines, J. L. Ponsford, and R. J. Stolwyk, "Development of a new self-awareness of falls risk measure (SAFRM)," Archives of Gerontology and Geriatrics, vol. 59, no. 2, pp. 249-256, 2014.

[46] L. SurveyMonkey, SurveyMonkey ${ }^{\circledR}$, SurveyMonkey, Palo Alto, Calif, USA, 2014.

[47] W. H. O. Ageing and L. C. Unit, WHO Global Report on Falls Prevention in Older Age, World Health Organization, 2008.

[48] D. P. Gill, G. R. Jones, G. Zou, and M. Speechley, "Using a single question to assess physical activity in older adults: a reliability and validity study," BMC Medical Research Methodology, vol. 12, no. 1, p. 20, 2012.

[49] R. Atkinson and J. Flint, "Accessing hidden and hard-toreach populations: snowball research strategies," Social Research Update, vol. 33, no. 1, pp. 1-4, 2001.

[50] StataCorp L, Stata Version 14.0, StataCorp LP, College Station, Tex, USA, 2015.

[51] E. W. Steyerberg, M. J. C. Eijkemans, J. C. Van Houwelingen, K. L. Lee, and J. D. F. Habbema, "Prognostic models based on literature and individual patient data in logistic regression analysis," Statistics in Medicine, vol. 19, no. 2, pp. 141-160, 2000.

[52] R. M. Leipzig, R. G. Cumming, and M. E. Tinetti, "Drugs and falls in older people: a systematic review and meta-analysis: II. Cardiac and analgesic drugs," Journal of the American Geriatrics Society, vol. 47, no. 1, pp. 40-50, 1999.

[53] R. M. Leipzig, R. G. Cumming, and M. E. Tinetti, "Drugs and falls in older people: a systematic review and meta-analysis: I. Psychotropic drugs," Journal of the American Geriatrics Society, vol. 47, no. 1, pp. 30-39, 1999.

[54] J. D. Moreland, J. A. Richardson, C. H. Goldsmith, and C. M. Clase, "Muscle weakness and falls in older adults: a systematic review and meta-analysis," Journal of the American Geriatrics Society, vol. 52, no. 7, pp. 1121-1129, 2004.

[55] S. W. Muir, K. Berg, B. Chesworth, N. Klar, and M. Speechley, "Quantifying the magnitude of risk for balance impairment on falls in community-dwelling older adults: a systematic review and meta-analysis," Journal of Clinical Epidemiology, vol. 63, no. 4, pp. 389-406, 2010.

[56] J. C. Woolcott, K. J. Richardson, M. O. Wiens et al., "Metaanalysis of the impact of 9 medication classes on falls in elderly persons," Archives of Internal Medicine, vol. 169, no. 21, pp. 19521960, 2009.

[57] F. Bloch, M. Thibaud, B. Dugué, C. Brèque, A.-S. Rigaud, and G. Kemoun, "Psychotropic drugs and falls in the elderly people: updated literature review and meta-analysis," Journal of Aging and Health, vol. 23, no. 2, pp. 329-346, 2011.

[58] L. Letts, J. Moreland, J. Richardson et al., "The physical environment as a fall risk factor in older adults: systematic review and meta-analysis of cross-sectional and cohort studies," Australian Occupational Therapy Journal, vol. 57, no. 1, pp. 51-64, 2010.

[59] S. W. Muir, K. Gopaul, and M. M. Montero Odasso, "The role of cognitive impairment in fall risk among older adults: a systematic review and meta-analysis," Age and Ageing, vol. 41, no. 3, Article ID afs012, pp. 299-308, 2012.
[60] T. Kvelde, C. McVeigh, B. Toson et al., "Depressive symptomatology as a risk factor for falls in older people: systematic review and meta-analysis," Journal of the American Geriatrics Society, vol. 61, no. 5, pp. 694-706, 2013.

[61] S. R. Lord, "Visual risk factors for falls in older people," Age and Ageing, vol. 35, supplement 2, pp. ii42-ii45, 2006.

[62] M. E. Tinetti, M. Speechley, and S. F. Ginter, "Risk factors for falls among elderly persons living in the community," The New England Journal of Medicine, vol. 319, no. 26, pp. 1701-1707, 1988.

[63] K. Rapp, E. Freiberger, C. Todd et al., "Fall incidence in Germany: results of two population-based studies, and comparison of retrospective and prospective falls data collection methods," BMC Geriatrics, vol. 14, no. 1, article 105, p. 1, 2014.

[64] E. Barry, R. Galvin, C. Keogh, F. Horgan, and T. Fahey, "Is the Timed Up and Go test a useful predictor of risk of falls in community dwelling older adults: a systematic review and meta-analysis," BMC Geriatrics, vol. 14, no. 1, article 14, 2014.

[65] Panel on Prevention of Falls in Older Persons and American Geriatrics Society and British Geriatrics Society, "Summary of the updated American Geriatrics Society/British Geriatrics Society clinical practice guideline for prevention of falls in older persons," Journal of the American Geriatrics Society, vol. 59, no. 1, pp. 148-157, 2011. 


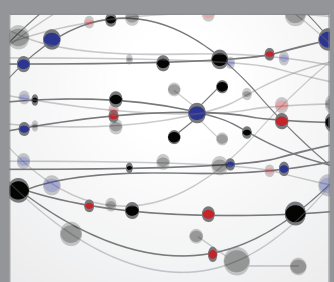

The Scientific World Journal
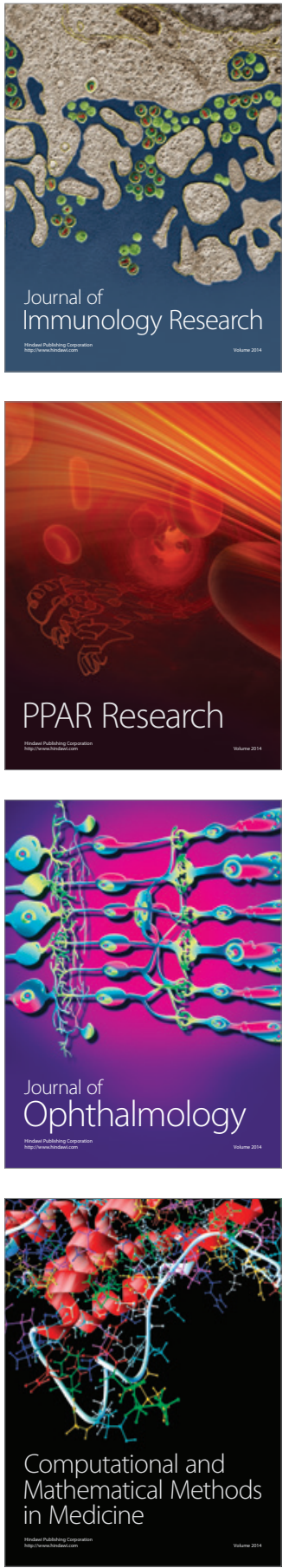

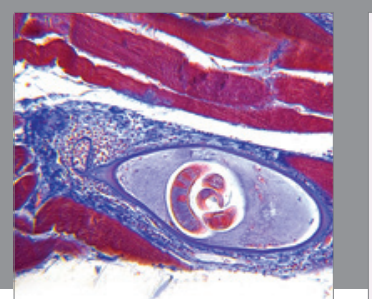

Gastroenterology Research and Practice

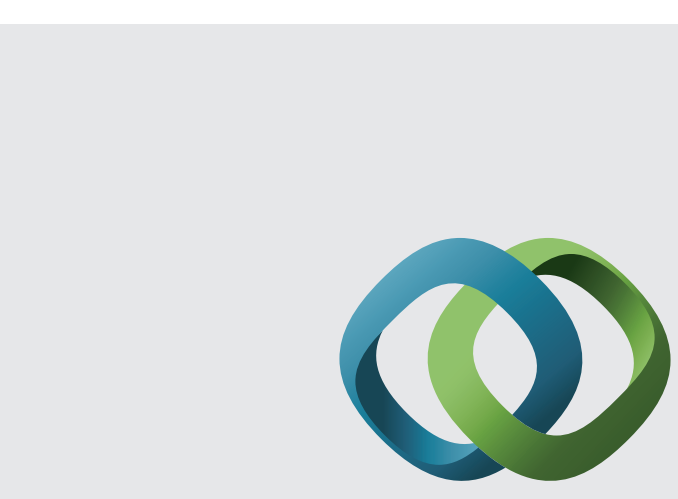

\section{Hindawi}

Submit your manuscripts at

http://www.hindawi.com
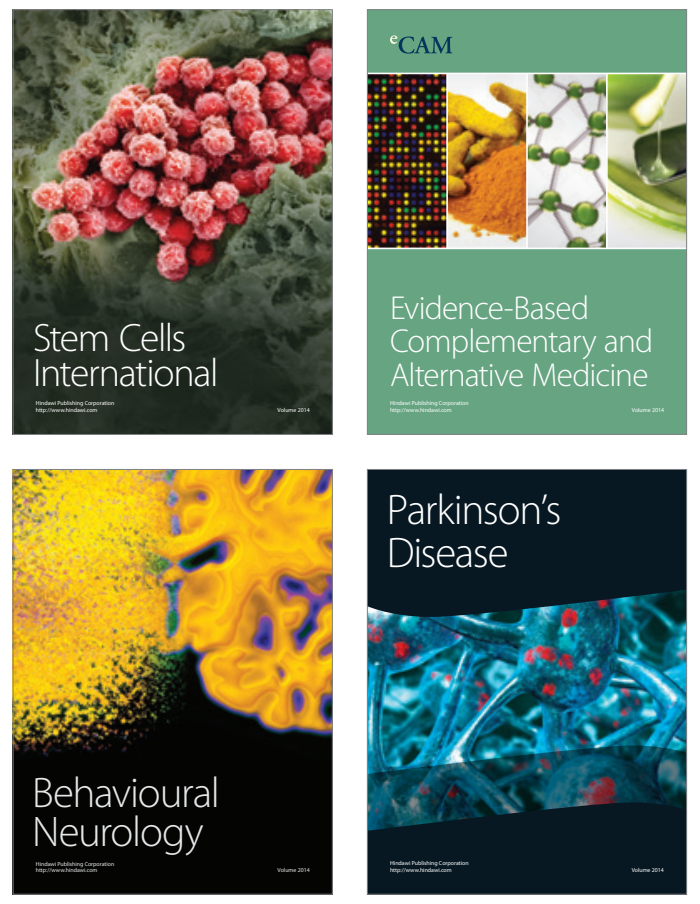
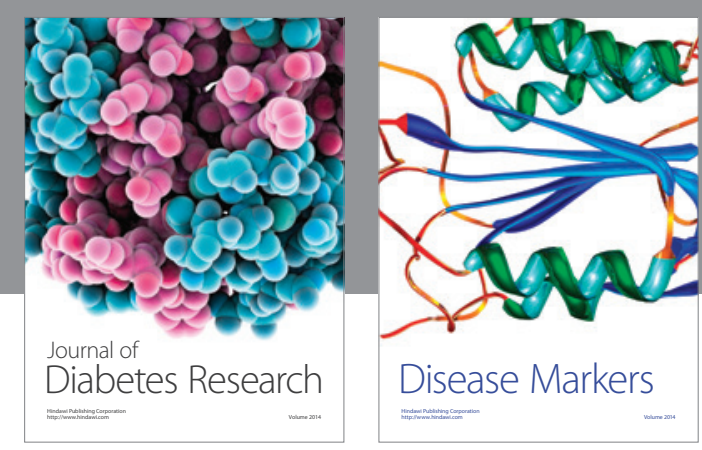

Disease Markers
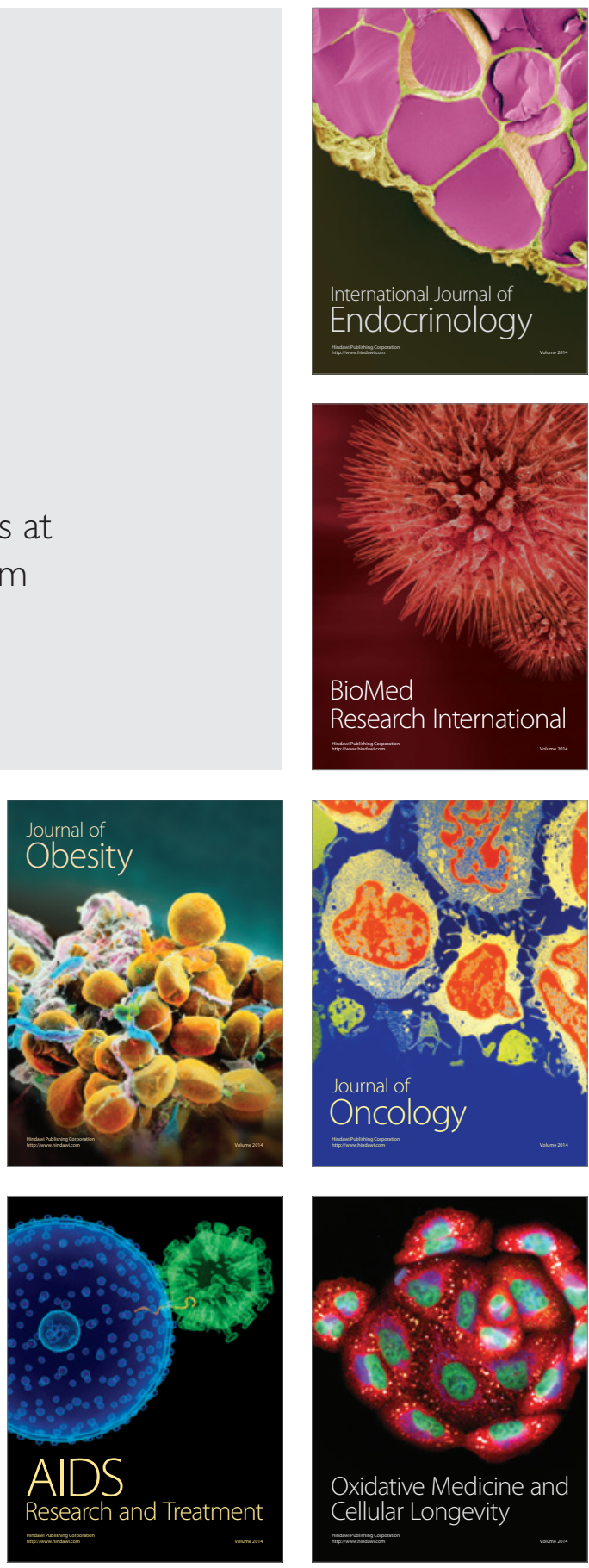